\title{
EL RISO RUBRO DE LAS
} LIAMAS.

\section{TREINTA POEMAS DE GUIMAR ÃES ROSA}

Selección, traducción y presentación de Manuel Barrós*

mfbarrosa@gmail.com

Pontificia Universidad Católica del Perú

Resumen: En esta oportunidad, Manuel Barrós presenta y traduce una selección de poemas de Magma (1997), poemario del escritor brasileño João Guimarães Rosa. Estos dan a conocer la primera obra que el autor escribió y por la cual ganó el premio de poesía de la Academia Brasileira de Letras en 1936. Como el libro permaneció inédito hasta 1997, fue póstumamente que el autor fue conocido como un poeta en verso y no solo en prosa. Al publicar estos poemas, el traductor amplía el panorama que de la obra de Guimarães Rosa se tiene en el Perú y en Latinoamérica.

Palabras clave: João Guimarães Rosa, Magma, poesía brasileña, literatura brasileña, traducción peruana.

* Manuel Barrós es sociólogo, investigador y traductor. Ha publicado traducciones de distintos escritores y poetas en revistas y, junto con Óscar Limache, Doze noturnos da Holanda / Doce nocturnos de Holanda (Ediciones Andesgraund, 2016; 2018) de Cecília Meireles, en Santiago de Chile. 


\title{
THE RED SMILE OF THE FLAMES. GUIMARÃES ROSA'S THIRTY POEMS
}

\begin{abstract}
In this opportunity, Manuel Barrós introduces and translates a selection of poems of Magma [Magma] (1997), Brazilian writer João Guimarães Rosa’s book of poetry. These poems let know the first work that he wrote and for which he won Academia Brasileira de Letras's price of poetry in 1936. As the book was unpublished until 1997, the author was knew, posthumously, like a poet in verses and not only in prose. Therefore, publishing these poems, the translator increases the scene of Guimarães Rosa’s literature in Peru and Latin America.
\end{abstract}

Keywords: João Guimarães Rosa, Magma, Brazilian poetry, Brazilian literatura, Peruvian translation.

E só ficará comigo o riso rubro das chamas, alumiando o preto das estantes vazias.

Joáo Guimarães Rosa, Magma (1997)

$\int \mathrm{i}$ oão Guimarães Rosa (Cordisburgo, 1908 - Rio de Janeiro, 1967) es una de las voces más importantes de la narrativa brasileńa en el siglo XX. Reconocido como un creador que mezcló de manera muy singular la cultura erudita y popular en sus obras, se lo considera fundamentalmente un hacedor de la lengua. Por eso mismo, nunca estuvo distante de la poesía. Solo la escribió en prosa, alcanzando uno de sus horizontes expresivos más grandes en Grande sertão: veredas (1956), su obra más conocida. Pero antes de que publicara sus historias, Guimarães Rosa escribió Magma, libro con el que ganó el premio de poesía de la Academia Brasileira de Letras en 1936. Aunque luego no renegó explícitamente de aquel primer libro por el que se dio a conocer, el autor tampoco lo difundió o publicó en vida. Guimarães Rosa murió —o "quedó encantado", como diría él— siendo conocido por sus obras en prosa. Posiblemente, esto se debe a que los poemas de Magma son, en su mayoría, sentimentales y candorosos. Es una obra con un lenguaje cuyas coordenadas son distintas a las del refinamiento barroco que el autor cultivó en sus libros de ficción.

Magma permaneció inédito hasta 1997, cuando la editorial Nova Fronteira lo publicó en Rio de Janeiro, con dibujos del artista plástico Poty. Y no solo se trató de una de 
las varias obras inéditas que se dieron a conocer póstumamente. Fue el primer libro ${ }^{1}$ que el autor escribió y que, por paradójico que parezca, era desconocido por la mayoría de lectores brasileños. En otros términos, pasaron treinta años para que Guimarães Rosa dejara de ser conocido solo como un narrador poeta para comenzar a ser leído como un creador que alguna vez — en una etapa de formación, a los veintiocho años — escribió poesía. De ahí que sea importante advertir que todos los poemas de Magma están escritos en esos renglones cortos llamados versos y ninguno en prosa. Acaso sea un detalle elocuente por comentar ya que refiere a la forma a través de la cual el autor consideró más propicia darle realidad textual a su sensibilidad.

Dicho esto, la presente publicación da a conocer en español una selección de poemas de $M a g m a^{2}$. Los treinta poemas traducidos han sido elegidos tanto por gusto personal como por ser representativos de la amplitud de temas y de formas expresivas con las que Guimarães Rosa los trata. Así, contenido y registro poético brindan un buen muestrario de los intereses literarios del autor y de los propósitos que se planteó en uno de sus primeros horizontes de escritura: entre otros, la vivacidad de la naturaleza, el desamor y el delirio, a través del epigrama, el haiku o el verso libre. Por eso, quien lea estos poemas podrá acercarse a la obra de Guimarães Rosa desde un libro inusual, quizá encontrando algún paralelismo con sus obras narrativas; quizá descubriendo insospechadas razones para comenzar a leer Magma o alguno de sus otros libros. Finalmente, anoto que al traducir me tomé algunas licencias, especialmente cuando prioricé la fluidez del contenido en español al rigor de una estructura métrica.

1 Cabe precisar que el primer libro que Guimarães Rosa publicó en vida fue Sagarana (1946). Es decir, diez ańos después de Magma, el autor recién publicaría una obra y sería en prosa.

2 Guimarães Rosa, J. (1997). Magma (1. ${ }^{a}$ ed.). Rio de Janeiro, Brasil: Nova Fronteira. 


\section{Luar}

De brejo em brejo, os sapos avisam:

- A lua surgiu!...

No alto da noite as estrelinhas piscam, puxando fios,

e dançam nos fios

cachos de poetas.

A lua madura

rola, desprendida,

por entre os musgos

das nuvens brancas...

Quem a colheu,

quem a arrancou

do caule longo

da Via-Láctea?...

Desliza solta...

Se lhe estenderes

tuas mãos brancas,

ela cairá...

\section{Imensidáo}

Cheiro salgado

尺 de um cavalo suado.

Quem galopa no mar?...

\section{Mundo pequeno}

O albatroz prepara

breve passeio

de Pólo a Pólo...

\section{Claro de luna}

De pantano en pantano,

los sapos dan avisos:

- ¡Apareció la luna...!

En lo alto de la noche las estrellitas parpadean,

jalando hilos,

y bailan en lo hilos

racimos de poetas.

La luna madura

rueda, desprendida,

por entre los musgos

de las nubes blancas...

¿Quién la tomó,

quién la arrancó

del tallo largo

de la Vía Láctea...?

Se desliza suelta...

Si le extendieres

tus manos blancas,

ella caerá...

\section{Inmensidad}

Olor salado

de un caballo sudoroso.

¿Quién galopa en el mar...?

\section{Mundo pequeño}

El albatros prepara

un breve paseo

de Polo a Polo... 


\section{Elegia}

Teu sorriso se abriu como uma anêmona entre as covinhas do rosto infantil.

Estavas de pijama verde, nas almofadas verdes, os pezinhos nus, as pernas cruzadas, pequenina, como um ídolo de jade que teve por modelo uma princesa anamita. Tuas mãos sorriam, teus olhos sorriam, o liso dos teus cabelos pretos sorria, e mesmo me sorriste,

e foi a única vez...

Não pude calçar, com beijos, os teus pezinhos,

e não pudeste caminhar para mim... Mas é bem assim que os meus sonhos te possuem.

\section{Alaranjado}

No campo seco, a crepitar em brasas, dançam as últimas chamas da queimada, tão quente, que o sol pende no ocaso, bicado

pelos sanhaços das nuvens, para cair, redondo e pesado, como uma tangerina temporá madura...

\section{Elegía}

Tu sonrisa se abrió como una anémona entre los hoyitos del rostro infantil.

Usabas una pijama verde, sobre las almohadas verdes,

los piececitos desnudos, las piernas cruzadas, pequeñita, como un ídolo de jade

que tuvo por modelo una princesa anamita.

Tus manos sonreían, tus ojos sonreían, el liso de tus cabellos negros sonreía, e incluso me sonreíste, y fue la única vez...

No pude calzar, con besos, tus piececitos, y no pudiste caminar hacia mí...

Pero es así como mis sueños te poseen.

\section{Anaranjado}

En el campo seco, crepitante de brasas, bailan las últimas llamas de la tierra quemada, tan caliente, que el sol pende en el ocaso, picoteado por los sanhaços de las nubes, para caer, redondo y pesado, como una mandarina que pronto ha madurado... 


\section{Amarelo}

Kuang-Ling,

pintor chinês de máscara de cera, feliz de ópio, e ébrio de dragóes, molha o pincel na água de ocre do Huang-Ho,

e, entre lanternas de seda, pinta e repinta, durante trinta anos, sulfúreos e asiáticos girassóis, na incrível porcelana de um jarrão dos Ming...

\section{Amarillo}

Kuang-Ling,

pintor chino de máscaras de cera, feliz de opio, y ebrio de dragones, moja el pincel en el agua de ocre de Huang-Ho, y, entre lámparas de seda, pinta y repinta, durante treinta años, sulfúreos y asiáticos girasoles, en la increíble porcelana de un jarrón de los Ming... 


\section{Desterro}

Eu ia triste, triste, com a tristeza discreta dos fatigados, com a tristeza torpe dos que partiram tendo despedidas, tâo preso aos lugares

de onde o trem já me afastara estradas arrastadas, que talvez eu não estivesse todo inteiro presente no horror dessa viagem.

Mas a minha tristeza pesava mais do que todos os pesos,

e era por causa de mim, da minha fadiga desolada,

que a locomotiva, lá adiante, ridícula e honesta, bracejava,

puxando com esforço vagóes quase vazios, com almas cheias de distância, a penetrar no longe.

A tarde subiu do chão para a paisagem sem casas, e o comboio seguia,

cada vez mais longe, mais fundo, a terra mais vermelha,

o esforço maior, as montanhas mais duras, como sabem ser duros os caminhos, pelos quais a gente vai, só pensando na volta... Coagulada em preto,

a noite isolou as coisas dentro da tarde, e o barulho do trem foi um rumor de soçobro no fundo de um mar sem tona.

Nem mesmo foi a noite: foi a ausência brusca e absurda do dia.

Tão definitiva e estranha, que eu me alegrei, esperando

o não continuar da vida,

o não-regresso da luz, o não-andar-mais do trem...

\section{Destierro}

Yo iba triste, triste, con la tristeza discreta de los fatigados, con la tristeza torpe de los que partieron teniendo despedidas,

tan preso a los lugares

de donde el tren ya me había alejado de calles arrastradas,

que quizá yo no estuviese todo entero presente en el horror de ese viaje.

Pero mi tristeza tenía un peso mayor que cualquier otro,

y era por mi culpa, por mi fatiga desolada, que la locomotora, allá adelante, ridícula y honesta, braceaba, jalando con esfuerzo vagones casi vacíos, con almas llenas de distancia, para penetrar en la lejanía.

La tarde se elevó del suelo al paisaje sin casas, y el convoy seguía,

cada vez más lejano, más hondo, la tierra más roja,

el esfuerzo más grande, las montańas más duras,

como saben ser duros los caminos,

por los cuales vamos, solo pensando en el regreso...

Coagulada en negro,

la noche aisló las cosas dentro de la tarde, y el ruido del tren fue un rumor de zozobra en lo hondo de un mar sin superficie.

$\mathrm{Ni}$ siquiera fue la noche: fue la ausencia brusca y absurda del día.

Tan definitiva y extraña, que yo me alegré, esperando

el no continuar de la vida,

el no-regreso de la luz, el no-andar-más del tren... 


\section{Lunático}

Vou abrir minha janela sobre a noite.

E já bem noite, a lua,

alta a um terço do seu arco,

terá de deslizar pelo meu quarto adentro,

e passear sobre o meu rosto, adormecido e

lívido,

quando eu sair a sonhar pelas estradas notur-

nas,

sem fim, sem marcos, nem encruzilhadas,

que levam à regiáo dos desabrigos...

Sonharei com mares muito brancos, de águas finas, como um ar dos cimos, onde o meu corpo sobrenada solto, por entre nelumbos que passam boiando... Ouvirei a rainha do País do Suave Sonho, cantando no alto sempre o mesmo canto, como a sereia do sempre mais alto... $\mathrm{E}$ a janela se fecha, prendendo aqui dentro o raio suave que prendia a lua...

Para que eu soçobre no mar dos nenúfares grandes,

onde remoinham as formas inacabadas, onde vêm morrer as almas, afogadas, e onde os deuses se olham como num espelho...

\section{Lunático}

Voy a abrir mi ventana sobre la noche.

Y ya bien de noche, la luna, alta a un tercio de su arco,

habrá de deslizarse por mi cuarto adentro, y pasear sobre mi rosto, adormecido y lívido, cuando yo salga a soñar por las calles nocturnas, sin fin, sin fronteras, ni encrucijadas, que llevan a la región de los desabrigos... Sońaré con mares muy blancos, de aguas finas, como un aire de las cimas, donde mi cuerpo sobrenada suelto, por entre nelumbos que pasan bogando... Oiré a la reina del País del Suave Sueño, cantando en lo alto siempre el mismo canto, como la sirena de aquello siempre más alto... Y la ventana se cierra, asiendo aquí adentro el rayo suave que asía a la luna...

Para que yo zozobre en el mar de los nenúfares grandes,

donde se arremolinan las formas inacabadas, donde vienen a morir las almas, ahogadas, $\mathrm{y}$ donde los dioses se miran como en un espejo... 


\section{Sono das águas}

Há uma hora certa,

no meio da noite, uma hora morta,

em que a água dorme. Todas as águas dormem: no rio, na lagoa,

no açude, no brejão, nos olhos d'água.

nos grotôes fundos.

E quem ficar acordado,

na barranca, a noite inteira,

há de ouvir a cachoeira

parar a queda e o choro,

que a água foi dormir...

Águas claras, barrentas, sonolentas,

todas vão cochilar.

Dormem gotas, caudais, seivas das plantas,

fios brancos, torrentes.

O orvalho sonha

nas placas da folhagem.

E adormece

até a água fervida,

nos copos de cabeceira dos agonizantes...

Mas nem todas dormem, nessa hora

de torpor líquido e inocente.

Muitos hão de estar vigiando, e chorando, a noite toda,

porque a água dos olhos

nunca tem sono...

\section{Sueño de las aguas}

Hay una hora certera,

en medio de la noche, una hora muerta,

en la que el agua duerme. Todas las aguas duer-

men:

en el río, en el lago,

en la represa, en el pantanal, en los hontanares,

en las grandes y hondas grutas.

$Y$ quien quede despierto,

en la barranca, la noche entera,

ha de oír que la catarata

detiene la caída y el llanto,

que el agua se fue a dormir...

Aguas claras, lodosas, sońolientas,

todas van a descansar un poco.

Duermen gotas, caudales, savias de plantas,

hilos blancos, torrentes.

El rocío sueńa

en las láminas del follaje.

E incluso

adormece al agua que ha borboteado,

en los vasos junto a la cama de los que agoni-

zan...

Pero no todas duermen, en esa hora

de letargo líquido e inocente.

Muchos han de estar vigilando,

y llorando, toda la noche,

porque el agua de los ojos

nunca tiene sueńo... 


\section{Reportagem}

O trem estacou, na manhã fria, num lugar deserto, sem casa de estação: a parada do Leprosário...

Um homem saltou, sem despedidas, deixou o baú à beira da linha, e foi andando. Ninguém lhe acenou...

Todos os passageiros olharam ao redor, com medo de que o homem que saltara tivesse viajado ao lado deles...

Gravado no dorso do bauzinho humilde, náo havia nome ou etiqueta de hotel: só uma estampa de Nossa Senhora do Perpétuo Socorro...

O trem se pôs logo em marcha apressada, e no apito rouco da locomotiva gritava o impudor de uma nota de alívio...

Eu quis chamar o homem, para lhe dar um sorriso,

mas ele ia já longe, sem se voltar nunca, como quem não tem frente, como quem só tem costas...

\section{Reportaje}

El tren se detuvo, en la mañana fría, en un lugar desierto, sin estación: el paradero del Leprosario...

Un hombre saltó, sin despedirse, dejó el baúl al borde de la línea, y se fue andando. Nadie le hizo ningún gesto...

Todos los pasajeros miraron a su alrededor, con miedo de que el hombre que había saltado hubiera viajado al lado de ellos...

Grabado en el dorso del pequeño y humilde baúl, no había nombre o etiqueta de hotel: solo una estampa de Nuestra Señora del Perpetuo Socorro...

El tren pronto aceleró la marcha, y en el silbido ronco de la locomotora gritaba el impudor de una nota de alivio...

Quise llamar al hombre, para darle una sonrisa, pero él ya estaba lejos, sin volverse nunca, como quien no tiene frente, como quien solo tiene espalda... 


\section{Iniciaçáo}

E nem mais existirá a esperança do trágico...

E no vazio, em vão apelareis para as grandes catástrofes, para a vaidade do ranger de dentes, para o pavoroso das formas não de todo feitas, sob o terrível das forças verticais... Sumirão as espadas suspensas de fios, sumirá a mão que escreve nas paredes do festim velho, e a Esfinge dormirá nas areias eternas... Somente o segredo, acordado, no caminho claro, na encruzilhada de todos os caminhos, andando na tua frente, desvendado, mais difícil de crer do que de decifrar... Teu pensamento, tua fé e teu desejo, criando, à tua escolha, o teu destino... E se fores forte, olha bem para cima, para ver como é sorrindo que morre o teu Pai...

\section{Distância sentimental}

Mesmo ao sonhar contigo, só consigo que me ames noutro sonho dentro do meu sonho primitivo...

\section{Iniciación}

Y no existirá más la esperanza de lo trágico...

Y en el vacío, en vano apelarán a las grandes catástrofes, a la vanidad del rechinar de los dientes, a lo pavoroso de las formas no del todo hechas, bajo lo terrible de las fuerzas verticales... Desaparecerán las espadas suspendidas por hilos, desaparecerá la mano que escribe en las paredes del viejo festín, y la Esfinge dormirá en las arenas eternas... Solo el secreto, despierto, en el camino claro, en la encrucijada de todos los caminos, andando en tu frente, descubierto, más difícil de creer que de descifrar... Tu pensamiento, tu fe y tu deseo, creando, según lo elijas, tu destino... Y si fueres fuerte, mira bien hacia arriba, para ver que, sonriendo, es como muere tu Padre...

\section{Distancia sentimental}

Incluso al soñar contigo, solo consigo que me ames en otro sueño dentro de mi sueńo primitivo... 


\section{Pudor estoico}

Acuado entre brasas,

um escorpiáo volve o dardo

e faz o hara-kiri...

\section{Definiçấo}

O cigarro de fumaça impalpável e brasa colorida,

que se fuma a si mesmo num cinzeiro, será um poeta?...

\section{Epigrama}

Ó lua cheia, ocular de um longo telescópio branco que devassa o país dos amores platônicos...

\section{Madrigal gravado en laca}

Quando a borboleta coroou a flor amarela os lírios, em ângulo reto com seus caules, fizeram uma profunda saudação...

\section{Falta de armas}

\section{Pudor estoico}

Acorralado entre las brasas, un escorpión vuelve el dardo y se hace el harakiri...

\section{Definición}

El cigarro de humo impalpable y brasa colorida,

que se fuma a sí mismo en un cenicero, ¿será un poeta...?

\section{Epigrama}

Oh luna llena, ocular de un largo telescopio blanco que irrumpe en el país de los amores platónicos...

\section{Madrigal grabado en laca}

Cuando la mariposa coronó la flor amarilla los lirios, en ángulo recto con sus tallos, hicieron una profunda reverencia...

\section{Falta de armas}

Dos caracoles habían chocado, levemente, sus casas, y revolvieron sus tentáculos, un día entero, pidiéndose mil disculpas... 


\section{Bergson}

Uma águia continua, ao sol do dia,

os vôos do mocho de Minerva...

\section{Música de Schubert}

Sombras de amores

em bailado longínquo, num palco sem fundo como um fundo de espelho...

\section{Taumaturgo}

Muitos bichos reunidos?: um jardim de Hagenbeck.

Ou, quem sabe, talvez, a Arca de Noé...

Mas um gênio os dirige?: um livro de Kipling...

\section{Justificação}

Ponham o Amazonas ao pé do Himalaia, e ali nascerá, depressa,

uma raça de homens pequeninos...

\section{Paisagem}

A cascavel chocalha na moita, anunciando grátis, um destino certo...

\section{Bergson}

Un águila continúa,

al sol del día,

los vuelos del búho de Minerva...

\section{Música de Schubert}

Sombras de amores

en un lejano baile teatral, en un palco sin

fondo

como un fondo de espejo...

\section{Taumaturgo}

¿Muchos animales reunidos?: un jardín de Hagenbeck.

O, quién sabe, quizá, el Arca de Noé...

¿Pero algún genio los dirige?: un libro de Kipling...

\section{Justificación}

Pongan el Amazonas al pie del Himalaya, y allí nacerá, deprisa,

una raza de hombres pequeñitos...

\section{Paisaje}

El cascabel hace ruido en el matorral, anunciando

de cortesía, un destino certero... 


\section{Impaciência}

(Duas variaçóes sobre o mesmo tema)

\section{I}

Eu queria dormir

longamente...

(um sono só...)

Para esperar assim

o divino momento que eu pressinto, em que hás de ser minha...

Mas...

e se essa hora

não devesse chegar nunca?...

Se o tempo,

como as outras cousas todas,

te separa de mim?!...

Então...

ah!, então eu gostaria

que o meu sono,

friíssimo e sem sonhos

(um sono só...)

não tivesse mais fim...

\section{II}

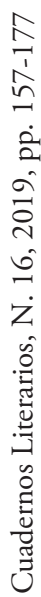

\section{Impaciencia}

(Dos variaciones sobre el mismo tema)

\section{I}

Yo quería dormir

largamente...

(solo un sueño...)

Para esperar así

el divino momento que presiento,

en el que has de ser mía...

Pero...

¿y si esa hora

no debiera llegar nunca...?

Si el tiempo,

como todas las otras cosas,

¡¿te separa de mí...?!

Entonces...

¡ah!, entonces me gustaría

que mi sueño,

friísimo y sin sueños

(solo un sueño...)

nunca tuviera fin...

II

¡Si pudiera correr por fuera del tiempo, vertiginosamente,

con el futuro en frente,

saltándome tantas horas tediosas,

vacías de ti,

y volar así hasta el momento de todos los momentos,

en el que has de ser mía...! 
Mas...

e se esse minuto faltar

nas areias de todas as ampulhetas?...

E se tudo fosse inútil:

a máquina de Wells,

as botas de sete léguas do Gigante?!...

Então...

ah!, então eu gostaria

de desviver para trás, dia por dia,

para parar só naquele instante,

e nele ficar, eternamente, prisioneiro...

(Tu sabes, aquele instante em que sorrias e me fizeste chorar...)
Pero...

¿y si ese minuto falta

en las arenas de todos los relojes de arena...?

¿¿Y si todo fuese inútil:

la máquina de Wells,

las botas de siete leguas del Gigante...?!

Entonces...

¡ah!, entonces me gustaría

desvivir hacia atrás, día por día,

para detenerme solo en aquel instante,

y en él quedarme, eternamente, prisionero...

(Tú lo sabes, aquel instante en el que sonreías y me hiciste llorar...) 


\section{Ironia}

A noite fria,

no jardim fechado

joga convites para os namorados.

Um grilo sibila

seu estribilho

de tenor sem sono.

Esses vaga-lumes, abelhas sonâmbulas

de velinhas verdes,

vêm das corolas das estrelinhas

destilar orvalho

nos botôes de jasmim.

Tudo calado

no jardim fechado...

Beija-me, querida,

nesta noite fria,

toda de alegria...

Não queres beijar-me?...

Queres ir embora?

Perdoa... Eu pensava

que gostasses de mim...

Quanta ironia

nesta noite fria,

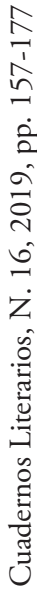

\section{Ironía}

La noche fría,

en el jardín cercado

brinda convites a los enamorados.

Un grillo silba

su estribillo

de tenor sin sueño.

Esas luciérnagas, abejas sonámbulas

de velitas verdes,

vienen de las corolas de las pequeñas estrellas

a destilar rocío

en los botones de jazmín.

Todo callado

en el jardín cercado...

Bésame, querida,

en esta noche fría,

toda de alegría...

¿No quieres besarme...?

¿Quieres irte?

Perdona... Pensaba

que yo te gustaba...

Cuánta ironía

en esta noche fría,

en la oscuridad del jardín...

Las luciérnagas ya están parpadeando, van apagando las linternitas frías...

Y hace tanto frío que el grillo endeble

ya desafina

en su flautín... 


\section{Delírio}

No parque morno, um perfumista oculto ordenha heliotrópios...

Deixa aberta a janela...

Minhas mãos sabem de cor o teu corpo, e a alcova é morna...

Apaguemos a luz...

Náo sentes na tua boca

um gosto de papoulas?...

Passa o lenço de seda de tuas mãos sobre minha fronte,

e não me digas nada:

a febre está, baixinho, ao meu ouvido, falando de ti...

\section{Delirio}

En el tibio parque, un perfumista oculto ordeña heliotropos...

Deja abierta la ventana...

Mis manos conocen de memoria tu cuerpo, y la alcoba es tibia...

Apaguemos la luz...

¿No sientes en tu boca un sabor a amapolas...?

Pasa la sábana de seda de tus manos sobre mi frente,

y no me digas nada:

la fiebre está, bajita, en mi oído, hablando de ti... 


\section{Ausência}

$\mathrm{Na}$ almofada branca,

as sandálias sonham

com a seda dos teus pés...

Partiste...

Mas a alegria ainda ficou no quarto, talvez no ninho morno, calcado por teu corpo no leito desfeito...

Entardece...

Esfuziante e verde, um beija-flor entrou pela janela, (pensei que a tua boca ainda estivesse aqui...)

Do frasco aberto, vestidas de vespas, voam violetas..

E na almofada de seda, beijo as sandálias brancas, vazias dos teus pés...

\section{Gargalhada}

Quando me disseste que não mais me amavas, e que ias partir, dura, precisa, bela e inabalável,

\section{Ausencia}

En la almohada blanca, las sandalias sueñan con la seda de tus pies...

Partiste...

Pero la alegría aún quedó en el cuarto, quizá en el nido tibio, calcado por tu cuerpo en el lecho deshecho...

Se hace tarde...

Silbante y verde, Un picaflor entró por la ventana, (pensé que tu boca aún estuviera aquí...)

Del frasco abierto, vestidas de avispas, vuelan violetas...

Y en la almohada de seda, beso las sandalias blancas, vacías de tus pies...

\section{Carcajada}

Cuando me dijiste que ya no me amabas, y que ibas a partir, dura, precisa, bella e insensible, tan impasible como un verdugo, se dilató en mí el pavor de las cavernas vacías... Pero te miré directo a los ojos, bellos como el terciopelo de las orugas verdes, y porque ya hubieran lágrimas en mis ojos, tuve pena de ti, de mí, de todos, y me reí de la inutilidad de las torturas predestinadas, guardadas para nosotros, desde las tinieblas de los tiempos, cuando la inexperiencia de los Dioses aún no había creado el mundo... 


\section{Pavor}

Em torno a mim

círculos concêntricos se fecham, como as órbitas lentas de um corvo...

Tudo é torvo e pesado,

falta de ar e de amor...

Para mim já se apagou a última cor.

E a minha alma se enfurna

em poços velhos de hulheiras,

de onde foi tirado e queimado o carvão todo.

Como um cego

que dormisse na treva, amedrontado,

para sonhar que mais uma vez cegou...

\section{Pavor}

En torno de mí

círculos concéntricos se cierran, como las órbitas lentas de un cuervo...

Todo es torvo y pesado,

falta de aire y de amor...

Ya se borró, para mí, el último color.

Y mi alma se encorva

en viejos pozos de hullas,

de donde fue tomado y quemado todo el carbón.

Como un ciego

que durmiera en las tinieblas, atemorizado, para soñar que perdió la vista una vez más... 


\section{Angústia}

Estou com medo das roupas da noite, dos vultos quietos, das sombras das cousas, que pulam, longas, com pés táo longos, e de uma cousa fria, qualquer cousa grande, que lá do longe, do não sei onde, vem vindo para mim.

Talvez do fundo das grandes matas por onde andei,

talvez da terra das cousas vivas que eu enterrei, talvez dos cantos do quarto escuro da minha infância,

talvez das cavernas de dragóes negros de livros que li...

Vem vindo, e o vento está uivando, vem vindo, e os cachorros, estâo soluçando, vem vindo da treva, para me agarrar...

Talvez ela queira roubar meu amor, talvez lembrar-me cousas passadas, talvez buscar-me para a escuridão... Já está perto, já vem pesando, vem me apalpando, vem me apartando, vem de uma cova, para me enterrar...

\section{Angustia}

Tengo miedo de los ropajes de la noche, de los cuerpos quietos, de las sombras de las cosas, que saltan, extensas, con pies tan largos, y de alguna cosa fría, cualquier cosa grande, que allá de lejos, de no sé dónde, viene llegando hacia mí.

Quizá del fondo de los grandes bosques por donde anduve,

quizá de la tierra de las cosas vivas que enterré, quizá de los cantos del cuarto oscuro de mi infancia,

quizá de las cavernas de dragones negros de libros que leí...

Viene llegando, y el viento está aullando, viene llegando, y los perros, están sollozando, viene llegando de las tinieblas, para tomarme... Quizá ella quiera robar mi amor, quizá recordarme cosas pasadas, quizá buscarme en la oscuridad... Ya está cerca, ya se hace pesada, viene palpándome, viene apartándome, viene de una cueva, para enterrarme... 


\section{Bibliocausto}

Que a minha mão não trema

ao deitar no fogo forte e primitivo

todos os traidores

que me deram veneno.

Queimarei o frio

geometrizador da vida

lapidada através de lentes bem polidas

(ah, o horror daquela pedra voando, tangida pela mão de não sei que demônio, e a pensar, pelo espaço, que ainda tem arbítrio!...)...

Queimarei o detrator, maníaco e vaidoso,

que quis deter a vida numa câmara lenta, para a tingir depois numa câmara escura (ah, o inferno galopando às doidas, nos cavalos sem freios da vontade cega e sem destino!...)...

Queimarei o louco,

ébrio de orgulho, raivoso de fraqueza, que destilava haxixe em frascos verdes na paisagem alpina (ah, o prazer com que ainda o queimaria em cada uma das voltas pavorosas do seu Eterno Retorno!....)...

E só ficará comigo o riso rubro das chamas, alumiando o preto das estantes vazias.

Porque eu só preciso de pés livres, de mãos dadas, e de olhos bem abertos...

\section{Bibliocausto}

Que mi mano no tiemble

al recostar en el fuego fuerte y primitivo a todos los traidores

que me envenenaron.

Quemaré el frío geometrizador de la vida lapidada a través de lentes bien pulidos (jah, el horror de aquella piedra volando, tocada por la mano de no sé qué demonio, y pensando, en el espacio, que aún tiene albedrío...!)...

Quemaré al detractor, maniaco y vanidoso, que quiso detener la vida en una cámara lenta, para teñirla después en una cámara oscura (¡ah, el inferno galopando alocadamente, en los caballos sin riendas de la voluntad ciega y sin destino...!)...

Quemaré al loco, ebrio de orgullo, rabioso de flaqueza, que destilaba hachís en frascos verdes en el paisaje alpino (jah, el placer con el que aún lo quemaría en cada uno de los regresos pavorosos de su Eterno Retorno...!)...

Y solo quedará conmigo

el riso rubro de las llamas, alumbrando lo negro de los estantes vacíos.

Porque solo necesito pies libres, andar de la mano, y con los ojos bien abiertos... 